\title{
Chances in the Brain Cells, From Epigenetic To the Future
}

\section{Soraya L. Valles*}

Department of Physiology, Faculty of Medicine, University of Valencia, Spain

Both oxidative damage and inflammation are elevated in brain from neurodegenerative patients [1], but their pathogenic significance remains unclear. Central nervous system has its own resident immune system, in which glial cells not only serve such as supportive and nutritive roles for neuron cells, also engage in several inflammatory processes that defend the central nervous system from pathogens and help it to recover from stress and injury [2,3]. Normal glial functions can sometimes result in a serious and chronic neuro-inflammatory cycle that promotes neurodegenerative diseases, constituent a viable target for the discovery or development of neurodegenerative diseases, such as in Alzheimer's disease protecting neurons in the mixer culture from the toxic action (Aguirre-Rueda et al., in peer review) and this point of view needs more research investigation. Astrocytes protect neurons by an increase in mitochondriogenesis thereby obtaining a better processing of oxidative stress and an efficient inflammation control (Aguirre-Rueda et al., in peer review). The importance of glial cell-propagated inflammation disorders has been seen as a bystander effect, or epiphenomenon, occurring when damaged neurons develop an activation response by glial cells. Wyss Corey and his collaborators demonstrateda phagocytosis process does it by astrocytes to eliminate and destroy $A \beta$ peptide plates and Valles group showed antiinflammatory effects after $A \beta$-induction in astrocytes [2,4,5]. For us astrocytes will be the first differentiate cells to death after injury, but is difficult to kill astrocytes and these cells had been reformed by the evolution to be stronger in front of damage to protect all the cells inside our brain. That is the reason to notice astrocytes always stronger than neurons in all of the viability assays used for us and others.

In glia many changes comparing to neuron and with other cells outside the brain has occurred during years and years. For example, TFAM in astrocytes might have multiple roles in protecting mtDNA against toxic products First, as a member of the high-mobility group of protein, TFAM could cover the entire region of mtDNA to form the nucleoid structure, protecting mtDNA from oxidative or inflammation modifications. Second, TFAM could maintain mtDNA copy number by binding $\mathrm{mtDNA}$ in the form of the nucleoid structure. Moreover, TFAM could initiate mtDNA transcription to induce mitochondrial biogenesis, which might effectively compensate the mitochondrial dysfunction and explaining mitochondrial DNA instability and metabolic shift in human cancer [6] (Valles et al., in peer review).Another point of view in recent works indicates that SIRT-1 influences growth-factor responses and maintenance of stem cells and also appears to influence lineage cell-fate decisions of stem cells via redox status, so not only will be important the differentiated astrocytes also will be so important the response of the stem cells inside the brain to the damage. And at last we do not forget that astrocytes have a special capacity they can return to a quiescent phenotype and a non-differentiated state, so they can convert to neurons if necessary. So changes in epigenetic and in the response of glia to damage will be crucial to recover from a illness in our brain. In the healthy brain, astrocytes provide essential services for brain homeostasis and neuronal function and also remove all toxic products, at night principally, when they are reactive astrocytes, prepared to attack virus and microorganisms. Why research community is only looking for neuron works? Why don't we investigate the role of glia in brain? Many people are thinking about it; let's see the future of research brain. In the next century we probably discover that the role of astrocytes will be wonderful for research community and perhaps looking for the nonqualification cells we realize how qualified they are. Astrocytes have a special protein exclusive for them, GFAP, glial fibrillary acidic protein expressed also in radial glia, but in a few \%. In astrocytes the protein is des-metilated when astrocytes start to differentiate from radial glia and has the same function, or not, that vimentine, transporting proteins across the cells and ions. Adult neurogenesis has advantage in front of damage and we need to know the normal range of this recharge because only understanding the regulation mechanisms of the process we will be able to understand our brain. To evaluate the influence of stem cells to replace brain cells in all diseases will be an important point in the future. The true role of astrocytes is not only one and we can dream with the beautiful astrocytes, such Einstein dream with the duality of energy and material.Perhaps are working in memory, reparation cells, and synapsis together and with neurons, perhaps they can control cancer, control neurogenesis and at last control all our body. The research community will fell so exiting about it. We have now a dream, please run with us to the future.

\section{References}

1. Vallés SL, Borrás C, Gambini J, Furriol J, Ortega A, et al. (2008) Oestradiol or genistein rescues neurons from amyloid beta-induced cell death by inhibiting activation of p38. Aging Cell 7: 112-118.

2. Valles SL, Dolz-Gaiton P, Gambini J, Borras C, Lloret A, et al. (2010) Estradio or genistein prevent Alzheimer's disease-associated inflammation correlating with an increase PPAR gamma expression in cultured astrocytes. Brain Res 1312: $138-144$.

3. Han X, Chen M, Wang F, Windrem M, Wang S, et al. (2013) Forebrain engraftment by human glial progenitor cells enhances synaptic plasticity and learning in adult mice. Cell Stem Cell 12: 342-353.

4. Vallés SL, Blanco AM, Pascual M, Guerri C (2004) Chronic ethanol treatment enhances inflammatory mediators and cell death in the brain and in astrocytes. Brain Pathol 14: 365-371.

5. Wyss-Coray $T$ (2006) Inflammation in Alzheimer disease: driving force, bystander or beneficial response? Nat Med 12: 1005-1015.

6. Valles SL, Benlloch M, Rodriguez ML, Mena S, Pellicer JA, et al. (2013) Stress hormones promote growth of B16-F10 melanoma metastases: an interleukin 6- and glutathione-dependent mechanism. J Transl Med 11: 72.
*Corresponding author: Soraya L. Valles, Department of Physiology, Faculty of Medicine, University of Valencia, Spain; Tel: 34-96-3864646, Fax: 34-96-3864642, E-mail: Lilian.Valles@uv.es

Received December 28, 2013; Accepted December 30, 2013; Published January 06,2013

Citation: Valles SL (2014) Chances in the Brain Cells, From Epigenetic To the Future. Gene Technology 3: e108. doi: 10.4172/2329-6682.1000e108

Copyright: (๑) 2014 Valles SL. This is an open-access article distributed under the terms of the Creative Commons Attribution License, which permits unrestricted use, distribution, and reproduction in any medium, provided the original author and source are credited. 